\title{
Biodiversity Prospecting and Conservation Programs: Models for International Collaborations
}

\author{
Barbara N. Timmermann \\ University Distinguished Professor \\ Chair, Department of Medicinal Chemistry \\ University of Kansas
}

$\mathrm{n}$ International Cooperative Biodiversity Groups (ICBG) Program was
awarded in 1993 for research into drug discovery from medicinal plants,
biodiversity conservation and economic development in Latin America. While biodiversity from arid lands is well known to produce a vast array of natural products as defensive agents and poisons, they have received much less attention than plants from the tropical rainforests as potential sources of drugs for human health. This project, funded by the U.S. government, has been undertaken in cooperation with universities and research institutions from the U.S.A., Argentina, Chile and Mexico, and U.S. pharmaceutical and agrochemical corporations. This ICBG program is unique in its emphasis on the United Nations Convention on Biological Diversity regarding the implementation of policies on conservation of natural resources, intellectual property rights and other issues of concern to host countries.

\section{INTRODUCTION}

Medicines from plants with biological/pharmacological activity have a long history of use in both traditional and modern societies as phytomedicines, herbal remedies, purified compounds approved by the Food and Drug Administration (FDA) and as starting materials for further chemistry or biocatalysis modifications (Jones et al., 2006; Butler, 2004; Balunas and Kinghorn, 2005; Koehn and Carter, 2005). Drug discovery from plants still provides important new drug leads against diverse diseases such as cancer, malaria, HIV/AIDS and tuberculosis (Butler, 2004; Newman et al., 2005).
However, drug discovery from plants faces many challenges, including legal and logistical difficulties involved in the collection of plant materials (Rosenthal, 2002; Soejarto et al., 2004), the lengthy and costly process of bioassay-guided fractionation, isolation and chemical characterization (Balunas and Kinghorn, 2005) and the elimination or reduction of natural product research programs at pharmaceutical corporations and U.S. federal agencies (Butler, 2004; Koehn and Carter, 2005).

A majority of new medicines derived from plants have been applied toward the treatment or prevention of cancer (Newman et al., 2003). Progress 
has been made in cancer chemotherapy, a considerable portion of which can be attributed to plant-derived drugs. Anticancer agents from plants currently in clinical use include four main compound classes and their synthetic and/or semi-synthetic derivatives: Vinca (or Catharanthus) indole alkaloids from Catharanthus roseus (L.) G. DON (Apocynaceae; formerly Vinca rosea L.), epipodophyllotoxins from Podophyllum peltatum L. (Berberidaceae), taxanes from Taxus brevifolia NUTT. (Taxaceae), and camptothecins from Camptotheca acuminata DECNE (Nyssaceae). Two other classes of compounds from plants are showing promising results in advanced clinical trials, namely, the combretastatins and their derivatives from Combretum caffrum KUNTZE (Combretaceae) and the homoharringtonine alkaloids from Cephalotaxus harringtonia C. $\mathrm{KOCH}$ (Cephalotaxaceae) [Newman et al., 2003]. Despite the major advances in caner prevention and treatment, new drugs are still needed, since some cancers have become resistant to currently available treatments and certain types of cancer lack appropriate drug treatments.

Beginning in 1993, the International Cooperative Biodiversity Groups (ICBG), a program administered by the Fogarty International Center (FIC), National Institutes of Health $(\mathrm{NIH})$, and supported through funds through NIH, National Science Foundation (NSF) and U.S. Department of Agriculture (USDA) Foreign Agricultural Service (FAS), started operation in an effort to integrate the following goals: improvement of human health through drug discovery, incentives for conservation of biodiversity, and development of new models of sustainable economic activity that focus on the environment, health, equity and democracy. The implementation of this program is based on the belief that the discovery and development of pharmaceutical and other useful agents from the world's biodiversity can, under appropriate circumstances, promote scientific capacity development and economic incentives to conserve the biological resources from which these products are derived (Fogarty International Center, 2004). The drug discovery effort is focused on diverse target organisms, comprising five (Eubacteria, Protoctista, Plantae, Fungi, Animalia) of the six kingdoms of overall biodiversity.

The ICBG entitled "Bioactive Agents from Dryland Biodiversity of Latin America" serves as a model for the implementation of the ICBG principles, which are, ultimately, the principles of the United Nations Convention of Biological Diversity (UNCBD). In the two phases of operation (1993-1998 and 1998-2005), and until the author moved to Kansas from Arizona, this ICBG consortium consisted of a US-based academic institution (University of Arizona), four Latin American academic and research institutions (Pontificia Universidad Catolica de Chile, Santiago, Chile; Instituto de Recursos Biologicos, Buenos Aires, Universidad Nacional de la Patagonia, and the Centro Nacional Patagonico, Chubut, Argentina; and Universidad Nacional Autonoma de Mexico), one US research institution (Institute of Tuberculosis Research, Chicago) and two US industrial partners 
(Wyeth Research-Pearl River, New York and Fort Dodge Animal Health-New Jersey). Based on this model, bioprospecting research continues at $\mathrm{KU}$ with new host country collaborations (e.g., Panama) under new institutional agreements.

This project has involved plant collection, extract and fraction preparation, screening of extracts and fractions in cytotoxicity and mechanismbased in vitro bioassays, dereplication of active plant species, activity-guided fractionation, compound isolation and structure elucidation, in vivo testing in animal models, lead optimization, and compound development. Although extensive data have been collected through the course of this project, this paper describes the different projects within the program in regard to plant procurement, drug lead discovery, conservation activities as well as intellectual property rights and issues of concern to host countries.

The drug discovery and development goal of this ICBG is to identify biologically active molecules from plants of arid and semi-arid ecosystems in Argentina, Chile, and Mexico as chemotherapeutic candidates for tuberculosis, cancer and other diseases of concern to developed and developing countries. In addition to scientific study, the work promotes economic growth in areas where the plants are collected, involves local populations wherever possible, collects indigenous knowledge about the plants and their uses, and works to conserve biological resources through educational programs.

\section{BOTANICAL COLLECTIONS AND INVENTORY}

Many xerophytic plants are known for their medicinal properties and for the complex arrays of natural products they manufacture as apparent adaptations to extreme conditions of heat, desiccation, ultraviolet radiation, and herbivory to which they are exposed. Arid-adapted plants are noteworthy by providing host plant defenses against infectious disease, parasitism or predation (Timmermann and Hoffmann, 1985; Hoffmann et al., 1993; Maatooq et al., 1996).

The ICBG program focused on plants from different regions in Latin America and allowed for the systematic screening of medicinal, endemic and local plants with a battery of high throughput biological assays. The feasibility of a plant-screening program depends on effective procurement strategies using a combination of random, taxonomic, ecological and ethnobotanical strategies.

In order to incorporate national priorities into the site selection process, regions of high interest for conservation as well as community development were considered as recommended by governmental and non-governmental conservation organizations in each host country. Plants collections were undertaken in diverse ecosystems such as the cold deserts and steppes of Patagonia and Tierra del Fuego, as well as the phytogeographical provinces of the Monte and the Chaco in Argentina; the hyper-arid desert of Atacama and the semi-arid and arid central Chile, and the drylands of central and western Mexico. 
This program was designed so that plant collections, inventories, and other activities were in agreement with the appropriate domestic and international laws, such as laws on endangered species (CITES) and plant conservation. When working in the natural areas of origin of the plants, permission was always sought at the national and local levels. In some cases, agreements were made with local non-governmental organizations and provincial governments in the source countries. A formal, written plant collection agreement was undertaken with source countries prior to all plant collections.

Voucher specimens for taxonomic identification and future reference were collected and deposited at all institutions in host countries and in various herbaria in the US. For most species, numerous anatomical parts (including leaves, twigs, flowers, fruits, roots, bark, and other parts, or combination of parts) were collected (called samples). Dried specimens were shipped to the US for chemistry research.

When available, local collaborators in the collection areas were contacted and interviewed about plant remedies from the local flora. This knowledge was gathered primarily to help insure preservation of this cultural knowledge, to increase the chance of drug discovery leads, to develop local phytomedicines and to maximize the potential of rewarding the local community with financial benefits.

Extensive ecological data, including edaphic, altitudinal, and climatic factors, were recorded during plant collections in order to build a database that allowed us to correlate the ecological conditions with biological activity. Further understanding of the relationships between plant profiles and biological activity lead us to more direct and informative plant collection endeavors currently underway. The relational database used in this research was NAPIS (NAtural Products Information System).

\section{EXTRACTION AND SCREENING ACTIVITIES}

Once a plant species was located in the wild, a necessary amount of aboveground biomass was collected to yield approximately $1 \mathrm{~kg}$ of dry weight of material to generate organic extracts according to established protocols. To date, more than 10,000 extracts were formatted into microtiter plates and tested for biological activity in a wide variety of sensitive, selective assay systems in a variety of therapeutic areas. About 45 different screens have been employed for the initial assays and for follow up studies. In order to maximize efficiency and avoid potential conflicts of interests, a wide assortment of mechanism-based, whole organism and enzyme-induction assays were employed in the primary screening program to detect lead extracts with interesting and desired mechanistic properties. All plant samples were subjected to a battery of biomedical bioassays using several automated, high throughput enzyme assays developed and performed at Wyeth (Pearl River, New York) and the Institute for Tuberculosis Research (Chicago) while the agrichemical and veterinary tests were performed at Fort Dodge Animal Health (Monmouth Junction, New Jersey). Therapeutic areas of potential 
target applications in human health included oncology, anti-infective, central nervous system, metabolic and inflammatory disease and women's health. An extensive battery of organisms resistant to a wide variety of clinically used antimicrobial agents were employed for secondary testing of active leads.

\section{BIOASSAY-GUIDED ISOLATION}

When biological activity was detected and confirmed for a sample in at least one screen it was considered a positive lead. Bulk plant collections in the order of one-to-three kilograms of dry biomass were obtained for these positive samples or hits following the initial screens. Active extracts were evaluated in a panel of secondary screens and by chemical dereplication for prioritization. Bioassay-guided fractionation of active extracts was conducted for isolation and identification of the active compound(s). Chemical novelty, activity in secondary functional assays, and in vivo results were used in the prioritization of active compounds. New active lead molecules were selected for structural modification to generate new analogs with enhanced activity and reduced toxicity.

High-performance liquid chromatography/mass spectrometry (HPLC/MS) dereplication involved offline fractionation/LC/MS analyses. Those compound classes found to be most active can be considered during dereplication processes in future drugdiscovery efforts from plants.

Active extracts were fractionated into 96-well plates by HPLC. Fractions were tested for biological activity and active fractions were analyzed using MS to detect inferred molecular weight (s) of active compounds. These molecular weights were then compared to those of known bioactive agents from within the same taxonomic genus or family using natural products databases (e.g., Natural Products ALERT (NAPRALERT), Beilstein, SciFinder Scholar, and the Dictionary of Natural Products). Extracts containing bioactive compounds not previously isolated or reported were prioritized for further fractionation.

$$
\text { Large-scale bioassay-guided }
$$

fractionation was conducted to isolate and identify active compounds. Fractionation was conducted using open, low pressure, and vacuum column chromatography (e.g., normal-phase and reversed-phase silica gel, alumina, and Sephadex LH-20). HPLC and TLC were also utilized as necessary. Active fractions underwent continued fractionation to isolate compound (s) responsible for activity.

Compounds were identified by various spectroscopic techniques including UV, IR, and proton and carbon nuclear magnetic resonance (NMR) spectroscopy, and low- and highresolutions mass spectrometry (MS). Additional 1D- and 2D-NMR experiments were performed as necessary to determine structures unambiguously. When necessary X-ray crystallography and circular dichroism (CD) were also utilized to determine absolute configuration.

Although the largest part of our drug discovery research remains confidential, we have been able to publish chemistry results in peer reviewed journals following the filing of a provisional patent application. To date, 
about 500 compounds were isolated and elucidated of which 60 are novel compounds (Waechter et al., 1998, 1999 a, b, c, 2001 a,b; Valcic et al., 1998, 1999, 2002; Flagg et al., 1999, 2000; Timmermann et al., 1999; Caldwell et al., 2000; Munoz et al., 2001 a,b; Mata et al., 2001, 2002, 2003; Gutierrez-Lugo et al., 2002; Rojas et al., 2003; Woldemichael et al., 2003 a, b, c, d; Gu et al., 2006; Khera et al., 2003, 2007). The chemical classes found include simple aromatics, benzopyrans, benzofurans, unusual flavonoids, mono-, sesqui-, di- and triterpenoids, steroids, monomeric, di-, and trimeric phenylpropanoids and alkaloids. Information regarding the relationship between compound classes and class diversity may be further utilized to support the continued search for bioactive compounds from plants.

The structural diversity of active compounds isolated during the course of this research also points towards the importance of continued exploration of plant secondary metabolites in the drug discovery process, since the structural diversity and compound characteristics of natural products are not readily accessible through synthetic or combinatorial chemistry

\section{INFORMATION AND}

\section{DISSEMINATION}

The goal of the information management and dissemination component has been to support the research, conservation, and economic growth efforts of the overall project by building information handling capabilities at all project sites and by promoting the exchange of information between the cooperating institutions. Based on a survey of all project participants in each country at the beginning of the project, specific objectives identified were to: 1 ) develop general project-related communications products; 2) build a plant database catalog integrated with bibliographic and geographic information systems (GIS) functions; and 3) provide technology transfer and training in the use of these information systems. Throughout the course of the project, these objectives have remained largely the same, although specific activities have changed and evolved according to newly identified needs and interests. A web site was designed to provide a complete historical record of the project in English as well as in Spanish and included lists of publications and presentations resulting from the project, the full-text of selected documents, slide shows of conservation activities and special features such as links to webversions of several databases.

One of the project's central goals was to address and promote biodiversity conservation and sustainable economic activity, including development of strategies for minimizing negative environmental impacts while ensuring that equitable economic and social benefits from discoveries accrue to the country, community, and organization which facilitated the discovery of the natural product. Several workshops were held to insure that biodiversity, intellectual property rights, and cultural issues were considered in the process of prospecting for plant resources (Timmermann and Montenegro, 1997; Suarez et al., 1999).

Conservation and development goals were closely linked to this ICBG's 
academic research process. The plants collected for drug discovery purposes formed only a part of the information gathering process. Research to support biodiversity management was integrated into independent research projects such as the study of adaptations of native plants to the local environment; facilitating plant regeneration following harvesting for medicinal purposes; as well as growth dynamics, interactions with pollinators, defensive mechanisms against predation, and other relevant fields.

\section{INFRASTRUCTURE BUILDING}

A considerable effort in this ICBG was directed towards infrastructurebuilding and professional training in the source countries to develop long-term collaborative and sustainable relationships between the institutions involved. Benefits associated in this project have been apparent from the start as evidenced by the support received by the affiliated academic institutions in the host countries. It was recognized that the advancement on basic knowledge on plant biodiversity and conservation was important to the academic programs of all institutions. Certain infrastructure improvements have been added such as laboratory and conservation equipment, vehicles, germplasm and herbarium facilities. University students (US and foreign) have been trained and were being given the opportunity to use the equipment and data for their academic theses and dissertations.

\section{COLLABORATION AGREEMENTS}

The successful collaboration of the members of this ICBG required detailed agreements among the various participants, which defined work and funding commitments, ownership of materials, licensing rights and distribution of future financial benefits, if any. This design of the agreements resembles a wheel in which the University serves as the hub of the wheel and each of the collaborators as a spoke (Rosenthal, 1997). Seven agreements had to be negotiated on an individual basis. The challenge of this construction was the necessity to assure that all agreements were consistent with the others. The advantage of the separate agreements was our ability to address specific concerns on an individual collaborator basis.

Each two-way agreement defined the scope of work obligations of the University and of the collaborator, responsibility for permits and for obtaining informed consent, the collection and preservation of data, ownership of inventions, confidentiality, funding support, bioassay screening, reports, responsibility to establish a sustainable agricultural source of the bioactive plant in the region of its collection, and collection and distribution of royalties to the participating parties.

Royalties, should there be any, will be divided into a "collector's share", an "inventor's share" and a "conservation share". The employing institutions of all named inventors of a patent will equally divide the "inventors share" (45\% of all royalties). Further distribution by the institutions to the inventors will be dictated by existing policies. Since collectors are not generally recognized as inventors, the collector will receive a separate "collector's share" (5\%) and the 
remaining (the largest) share (50\%) will be distributed to a conservation fund in the area of the collection of the country of collection.

It is important to realize that the probability that this or any other ICGB project will discover and develop a commercially viable drug is quite small. For example, it is estimated that it may require the evaluation of 50,000-100,000 compounds in order to obtain a single marketable drug (Kuhlmann, 1997). Not all leads will produce a drug; nearly all (49 or 50) of the compounds that show promise at an early stage in the development process will fail when evaluated in a more advanced animal model. Therefore, the real benefits from this type of collaborations are in the collaborative interactions established among the participating countries, the databases developed as a result of the project, the technology transfer and the training of students and faculty through active exchange programs.

\section{COMMUNITY DEVELOPMENT AND BENEFIT SHARING}

An important objective of this ICBG program was to promote local responsibility for the conservation of biological diversity. In particular, we were interested in deriving products from ecologically healthy, diverse habitats that will enhance the well being of the local people, as well as benefiting humanity generally. If an industrialized product is developed from plant material, the community from which the plant sample originated will have priority in producing raw material from in situ populations, if management allows a sustainable production. Cultivation of commercial crops in the priority community will be necessary if the natural population cannot sustainably produce sufficient material, as is very likely. Hence, the local community will benefit economically by additional jobs and tax revenue as well as by conserving the natural habitat.

This ICBG was actively involved in community work at the request of source country schools, local communities, agricultural extension stations, and nongovernmental organizations. Regular training workshops were provided on conservation of native plants to elementary and high school teachers and students as well as farmers and medicinal plant collectors and processors.

Many local communities became involved in the use of, and in the production of, herbal remedies. The Mexican and Chilean Health Departments (Ministerios de Salud), for example, are continuing the process of enforcing national regulations requiring the registry of these products. Such registration includes a monographic study of the botany, ethnobotany, chemistry, pharmacology and toxicology of each plant ingredient. The first effort in this direction was published in three monographs by our project and others are to follow (Pena et al., 1998; Montenegro et al., 1999, 2001).

Environmental trust funds have been established in each host country in order to administer any royalty that could be generated by products derived from this project. In addition, we continue collaborating with advisors of the Argentinean, Chilean and Mexican Senate's commissions that are drafting legislation on access and benefit sharing of biological resources. 


\section{CONCLUSIONS}

This summary used the Latin American ICBG program to illustrate a particular framework developed for research into drug discovery from natural products derived from medicinal plants of mostly xeric environments, biodiversity cataloging and conservation as well as economic development. As such, this ICBG has been specifically designed for the existing scientific, technological, cultural, geographical, legal and technological situations in Argentina, Chile and Mexico.

From our direct participation in the ICBG efforts in search for biologically active agents from terrestrial plants, we can conclude that such an endeavor is a very complex process that requires the involvement of not only scientific expertise, but also expertise in a variety of human activities including diplomacy, international laws and legal understandings, social sciences, politics, anthropology, sociology and knowledge of local language and culture.

In the long term, this project has built institutional and international relationships between the U.S. and developing countries that will continue to grow beyond the life of the project and will serve as an effective model for others who seek to develop similar relationships.

\section{ACKNOWLEDGEMENTS}

This program was supported by the grant 5 U01 TW00316-10 from the NIH, NSF and the USDA to BNT. The author is very grateful for the excellent contributions of the collaborating scientists as well as the laboratory contributions of the graduate, post-doctoral and undergraduate students and technical assistants. The contents are solely the responsibility of the author and do not represent the official views of the funding agencies.

\section{References}

1. Balunas, M. J. and Kinghorn, A.D. (2005). Life Sci. 78, 431.

2. Butler, M.S.(2004). J. Nat. Prod. 67, 2141.

3. Caldwell, C., Franzblau, S.G., Suarez, E. \& Timmermann, B.N. (2000) J. Nat. Prod. 63, 1611.

4. Flagg, M., Valcic, S., Montenegro, G., Gomez, M. \& Timmermann, B.N. (1999)

Phytochemistry, 52, 1345.

5. Flagg, M.L., Waechter, G.A., Davis, A.L., Montenegro, G. \& Timmermann, B.N. (2000) J. Nat. Prod. 63, 1689.

6. Fogarty International Center (2004) International Cooperative Groups. Available at http://www.fic.nih.gov/programs/icbg.html

7. Gu, J.-Q., Wang, Y., Franzblau, S., Montengro, G. \& Timmermann, B.N. (2006) Phytochem. Anal. 17, 102.

8. Gutierrez-Lugo, M-T., Singh, M.P., Maiese, W.M. \& Timmermann, B.N. (2002) J. Nat. Prod. 65, 872.

9. Hoffmann, J.J., Timmermann, B.N., McLaughlin, S.P. \& Punnapayak, H. (1993 Intl. J. Pharmacog. 31, 101.

10. Jones, W.P., Chin Y.-W. \& Kinghorn (2006) Curr. Drug Targets 7, 247.

11. Khera, S., Jolad, S.J., Carducci, M.D. \& Timmermann, B.N. (2003 Acta Crystallogr. Sect. E, 59, 1403.

12. Khera, S., Montenegro, G. \& Timmermann, B.N. (2007) Nat. Prod. Comm. 2, 969.

13. Koehn, F.E. \& Carter, G.T. (2005). Nat. Rev. Drug Discov. 4, 206.

14. Kuhlmann, J. (1997) Int. J. Clin Pharmacol.Ther. 35, 541.

15. Maatooq, G.T., Stumpf, D.K., Hoffmann, J.J., Hutter, L.K. \& Timmermann, B.N. (1996) Phytochemistry 41, 519.

16. Mata, R., Martinez, E., Bye, R., Morales, G., Singh, M.P., Janso, J.E., Maiese, W.M. \& Timmermann, B.N. (2001) J. Nat. Prod. 64, 911.

17. Mata, R., Rivero-Cruz, I., Rivero-Cruz, B., Bye, R. \& Timmermann, B.N. (2002) J. Nat. Prod. 65, 1030.

18. Mata, R., Bye, R., Linares, E., Macias, M., Rivero-Cruz, I., Perez, O. \& Timmermann, B.N. (2003) Phytochemistry 64, 285.

19. Montenegro, G., Pena, R.C., Mujica, A., Iturriaga, L., Gonzalez, L. \& Timmermann, B.N. (1999) Rev. Academia Colombiana de Ciencias Exactas, Fisicas y Naturales 23, 455.

20. Montenegro, G., Pena, R.C. \& Timmermann, B.N. (2001) Lawen 2, 8. 
21. Munoz, O., Pena, R.C., Ureta, E., Montenegro, G. \& Timmermann, B.N. (2001a) Z. Naturforsch. 56c, 269.

22. Munoz, O., Pena, R.C., Ureta, E., Montenegro, G., Caldwell, C. \& Timmermann, B.N. (2001b) Z. Naturforsch. 56c, 273.

23. Newman, D.J., Cragg, G. M. \& Snader, K.M. (2003), J. Nat. Prod. 66, 1022.

24. Pena, R.C., Timmermann, B.N., Iturriaga, L., Gonzalez, L. \& Montenegro, G. (1998) Rev Academia Colombiana, 22, 595.

25. Rojas, S., Acevedo, L., Macias, M., Toscano, R.A., Bye, R., Timmermann, B.N. \& Mata, R. (2003) J. Nat. Prod. 66, 221.

26. Rosenthal, J.P. (1997) Equitable sharing of biodiversity benefit agreements on genetic resources In: Proceedings of the OECD International Conference on Biodiversity Incentive Measures for Conservation and Sustainable Use of Biological Diversity, Cairns, Organization for Economic Cooperation and Development (OECD), pp. 253.

27. Rosenthal, J. (2002) Nature 416, 15.

28. Soejarto, D.D., Gyllenhaal, C., Fong, H.H., Xuan, L.T., Hiep, N.T., Hung, N.V., Bich, T.Q., Southavong, B., Sydara K. \& Pezzuto, J.M. (2004) J. Nat. Prod. 67, 294.

29. Suárez, E., Fortunato, R.H., Elechosa, M.A., Casamiquela, R., Saavedra, E. \& Timmermann, B.N. (1999) Aspectos Técnicos, Culturales, Políticos y Legales de la Bioprospección en Argentina, Proceedings of an International Workshop, Buenos Aires, San Lorenzo Press, pp. 1-174.

30. Timmermann, B.N. \& Hoffmann, J.J. (1985) Resins from Grindelia: a model for renewable resources in arid environments. In: Wickens GE, Goodin JR, Field DV, eds., Plants for Arid Lands, London, George Allen and Unwin Press, pp. 357-368.

31. Timmermann, B.N. \& Montenegro, G. (1997) Proceedings Taller Internacional Aspectos Ambientales, Eticos, Ideologicos, y Politicos en el Debate sobre Bioprospeccion y Uso de Recursos Geneticos en Chile, Santiago, Sociedad de Biologia de Chile, Vol. 5, pp. 1119.
32. Timmermann, B.N., Waechter, G.A., Valcic, S., Hutchinson, B., Henzel, J., Casler, C., Ram, S., Currim, F., Manak, R., Franzblau, S.G., Maiese, W.M., Galinis, D., Suarez, E., Fortunato, R., Saavedra, E., Bye, R., Mata, R. \& Montenegro, G. (1999). Pharm. Biol. 37, Supplement, 35.

33. Valcic, S., Montenegro, G. \& Timmermann, B.N. (1998) J. Nat. Prod. 61, 771.

34. Valcic, S., Montenegro, G., Mujica, A.M., Avila, G., Franzblau, S.G., Singh, M.P., Maiese, W.M. \& Timmermann, B.N. (1999) Z. Naturforsch. 54c, 406.

35. Valcic, S., Waechter, G.A., Eppler, C.M. \& Timmermann, B.N. (2002) J. Nat. Prod. 65, 1270.

36. Waechter, G.A., Franzblau, S.G., Montenegro, G., Suarez, E., Fortunato, R.H., Saavedra, E. \& Timmermann, B.N. (1998) J. Nat. Prod. 61, 965.

37. Waechter, G., Matooq, G., Hoffmann, J.J., Maiese, W.M., Singh, M.P., Montenegro, G. \& Timmermann, B.N. (1999a) J. Nat. Prod. 62, 1319.

38. Waechter, G., Valcic, S., Flagg, M.L., Franzblau, S.G., Montenegro, G., Suarez, E. \& Timmermann, B.N. (1999b) Phytomedicine 6, 341.

39. Waechter, G., Wangmaneerat, A., Caple, K.M., Montenegro, G. \& Timmermann, B.N. (1999c) Z. Naturforsch. 54c, 1140.

40. Waechter, G., Valcic, S., Franzblau, S.G., Suarez, E. \& Timmermann, B.N. (2001a) J. Nat. Prod. 64, 37.

41. Waechter, G., Franzblau, S.G., Montenegro, G., Hoffmann, J.J., Maiese, W.M. \& Timmermann, B.N. (2001b) J. Nat. Prod. 64, 1463.

42. Woldemichael, G.M., Singh, M., Maiese, W.M. \& Timmermann, B.N. (2003a) J. Nat. Prod. 66, 242.

43. Woldemichael, G.M., Singh, M., Maiese, W.M. \& Timmermann, B.N. (2003b) Z. Naturforsch $58 \mathrm{c}, 70$.

44. Woldemichael, G.M., Franzblau, S.G., Zhang, F., Wang, Y. \& Timmermann, B.N. (2003c) Planta Med. 69, 628.

45. Woldemichael, G.M., Montenegro, G. \& Timmermann, B.N. (2003d) Phytochemistry $63,853$. 